\title{
Carbon Based Solid-State Calcium Ion-Selective Microelectrode and Scanning Electrochemical Microscopy: A Quantitative Study of pH-Dependent Release of Calcium Ions from Bioactive Glass
}

\author{
Jyothir Ganesh Ummadi ${ }^{\dagger, I}$, Corey Downs ${ }^{\dagger, \uparrow}$, Vrushali S. Joshi ${ }^{\dagger}$, Jack Ferracane ${ }^{\ddagger}$, and \\ Dipankar Koley ${ }^{\dagger, *}$ \\ †Department of Chemistry, Oregon State University, Corvallis, Oregon 97331, United States \\ FDepartment of Restorative Dentistry, Oregon Health \& Science University, Portland, Oregon \\ 97239, United States
}

\begin{abstract}
Solid-state ion-selective electrodes are used as scanning electrochemical microscope (SECM) probes because of their inherent fast response time and ease of miniaturization. In this study, we report the development of a solid-state, low-poly(vinyl chloride), carbon-based calcium ionselective microelectrode ( $\mathrm{Ca}^{2+}$-ISME), $25 \mu \mathrm{m}$ in diameter, capable of performing an amperometric approach curve and serving as a potentiometric sensor. The $\mathrm{Ca}^{2+}$-ISME has a broad linear response range of $5 \mu \mathrm{M}$ to $200 \mathrm{mM}$ with a near Nernstian slope of $28 \mathrm{mV} / \log \left[\mathrm{a}_{\mathrm{Ca}}{ }^{2+}\right]$. The calculated detection limit for $\mathrm{Ca}^{2+}$-ISME is $1 \mu \mathrm{M}$. The selectivity coefficients of this $\mathrm{Ca}^{2+}$-ISME

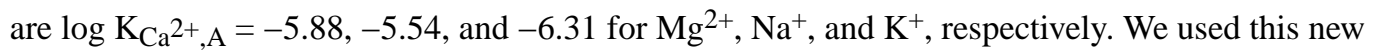
type of $\mathrm{Ca}^{2+}{ }_{-}$ISME as an SECM probe to quantitatively map the chemical microenvironment produced by a model substrate, bioactive glass (BAG). In acidic conditions ( $\mathrm{pH} 4.5$ ), BAG was found to increase the calcium ion concentration from $0.7 \mathrm{mM}\left(\left[\mathrm{Ca}^{2+}\right]\right.$ in artificial saliva) to 1.4 $\mathrm{mM}$ at $20 \mu \mathrm{m}$ above the surface. In addition, a solid-state dual SECM pH probe was used to correlate the release of calcium ions with the change in local $\mathrm{pH}$. Three-dimensional $\mathrm{pH}$ and calcium ion distribution mapping were also obtained by using these solid-state probes. The quantitative mapping of $\mathrm{pH}$ and $\mathrm{Ca}^{2+}$ above the $\mathrm{BAG}$ elucidates the effectiveness of $\mathrm{BAG}$ in neutralizing and releasing calcium ions in acidic conditions.
\end{abstract}

\section{Graphical Abstract}

\footnotetext{
*Corresponding Author: ; Email: Dipankar.Koley@ oregonstate.edu. IJ.G.U. and C.D. contributed equally to this work.

SUPPORTING INFORMATION

Cyclic voltammograms of dual SECM probe and calibration curves of $\mathrm{pH}$ and $\mathrm{Ca}^{2+}$ sensor probes.
} 


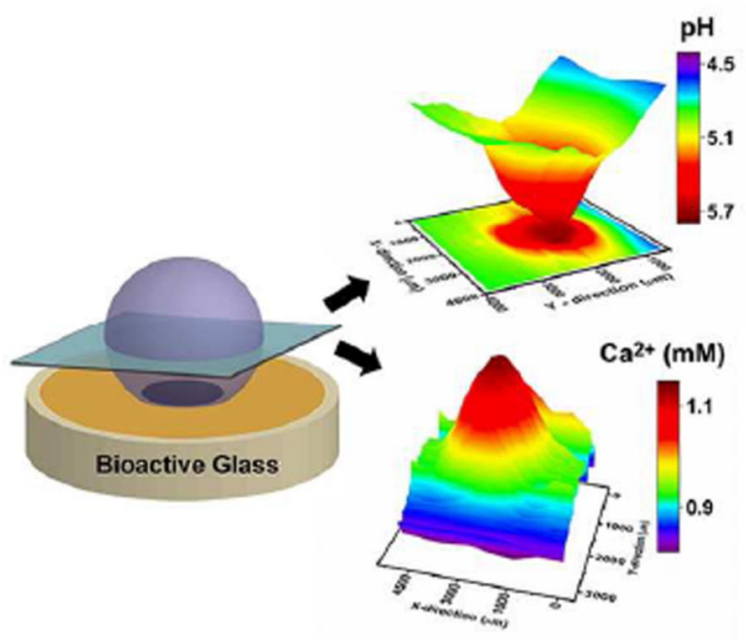

\section{INTRODUCTION}

A variety of materials, such as amalgam, resin, and polymer composites, are widely used as dental filling materials. Recently, bioactive glass (BAG), which has historically been used in bone repair and tissue engineering, has been introduced as a next-generation "smart" dental filling material. 1,2,3 A BAG-resin composite is capable of responding to its immediate surroundings by neutralizing the local $\mathrm{pH}$ drop and releasing calcium ions (Figure 1). ${ }^{4,5}$ Later, the calcium ions (in the presence of phosphate ions) precipitate as calcium phosphate, depending on the solubility at a given $\mathrm{pH}$. Thus, there is a need to develop new analytical methods to characterize the local chemical environment produced by BAG materials, especially to quantify the calcium ion release pattern at different local $\mathrm{pH}$ values.

Scanning electrochemical microscopy (SECM) has been widely used to map the local chemical environment by determining $\mathrm{Na}^{+}, \mathrm{K}^{+}, \mathrm{Ag}^{+}$, and other relevant ion concentrations on a wide variety of biological and material samples. $6,7,8,9$ The most common strategy for potentiometric detection of ions of interest is the use of a liquid/liquid interface (ITIES) SECM probe or an ionophore-based nonaqueous commercial cocktail as an SECM probe. ${ }^{10,11,12,13}$ However, the major obstacle in such a strategy is positioning the SECM probe at a known distance with the aid of an approach curve. To overcome such challenges, investigators have used a dual-electrode SECM probe comprising a potentiometric liquid membraned-based $\mathrm{K}^{+}$ion sensor and an amperometric gallium electrode for positioning and mapping ion release from a $0.1 \mathrm{M} \mathrm{KCl-filled} \mathrm{glass} \mathrm{capillary.}{ }^{14}$ In several studies, ${ }^{15,16}$ shear force has also been used to position the potentiometric SECM tip. A high-resolution $\mathrm{pH}$ profile was measured with a $500 \mathrm{~nm}$ diameter SECM tip composed of a commercially available proton ionophore II liquid membrane cocktail. A solid-state fast-response $\mathrm{pH}$ sensing SECM probe composed of an iridium oxide layer was reported in which the probe was positioned with an optical microscope because of its inability to perform an amperometric approach curve. ${ }^{17}$ Alternative strategies, such as polyaniline-coated carbon fiber electrodes, have also been demonstrated to act as $\mathrm{pH}$ sensors with a large working range from $\mathrm{pH} 2$ to $12.5 .^{18}$ 
Similar solid-state calcium ion-selective electrodes have been reported $19,20,21,22,23,24$ that used conducting polymer as a solid contact between electrode materials and the ion-sensing membrane. For example, Michalska et al. ${ }^{19}$ reported an improvement in the detection limit of close to $10^{-5} \mathrm{M}$ by using polyethylene dioxy thiophene as a solid contact between glassy carbon and a poly(vinyl chloride) (PVC)-based calcium ion-selective membrane containing ETH 1001 ionophore. However, similar challenges remain regarding the positioning of the potentiometric $\mathrm{Ca}^{2+}$-sensing probe for SECM applications. Etienne et al. ${ }^{25}$ reported the use of a shear-force-based technique to position the SECM probe at a known distance from the substrate, as their $\mathrm{Ca}^{2+}$ probe was purely a PVC-based commercially available cocktail from Sigma-Aldrich. However, no quantitative mapping of $\left[\mathrm{Ca}^{2+}\right]$ distribution from the dissolution of calcite crystals was reported. An alternative solution to the SECM probe positioning effort is to use a dual-function SECM probe, i.e. the same probe capable of functioning as an amperometric (to perform an approach curve) and as a potentiometric sensor. Horrocks et al. ${ }^{26}$ reported one such dual-functioning (amperometry and potentiometry) SECM probe made of antimony to map the $\mathrm{pH}$ variation due to water reduction above a platinum ultramicroelectrode (Pt-UME), as well as the $\mathrm{pH}$ gradient produced by the metabolism of the immobilized yeast cells. ${ }^{26}$ Similarly, carbon paste could act as a dual-function SECM probe, as demonstrated by the use of a $25 \mu \mathrm{m}$ diameter $\mathrm{Cu}^{2+}$ selective electrode composed of thiuram-containing carbon paste reported in one study. ${ }^{27}$ The probe was used to map $\mathrm{Cu}^{2+}$ dissolution from a copper substrate. However, to our knowledge, no SECM study using a dual-function (i.e. potentiometric measurements besides performing amperometric approach curve), solid-state calcium ion-selective microelectrode $\left(\mathrm{Ca}^{2+}-\mathrm{ISME}\right)$ has been reported.

In the present study, we used a solid-state $\mathrm{pH}$ and $\mathrm{Ca}^{2+}$-ISME SECM probe to quantitatively map the local $\mathrm{pH}$ gradient and the corresponding calcium ion release from BAG dental composites. A dual electrode, consisting of two $25 \mu \mathrm{m}$ diameter Pt electrodes, served as an SECM pH probe. One of the two Pt electrodes of this probe was modified with polyaniline and used as a pH sensor, and the other bare Pt electrode was used as a redox sensor. In addition, a new carbon paste containing ETH $129\left(\mathrm{Ca}^{2+}\right.$ ionophore $)$ was used as a $\mathrm{Ca}^{2+}$ sensor to detect calcium ions and to perform an amperometric probe approach curve to determine the tip-substrate (BAG) distance.

\section{MATERIALS AND METHODS}

\section{Chemicals}

ETH $129\left(\mathrm{Ca}^{2+}\right.$ ionophore) and high molecular weight Poly (vinyl chloride) (PVC) were purchased from Sigma Aldrich. 1-Nitro-2-(n-octyloxy)benzene (NPOE) and aniline $\left(\mathrm{C}_{6} \mathrm{H}_{5} \mathrm{NH}_{2}\right)$ were purchased from Alfa Aesar and Macron, respectively. Bis(2ethylhexyl)sebacate (DOS) and potassium tetrakis(4-chlorophenyl)borate (KTPIB) were purchased from TCI America. Tetrahydrofuran (THF) was purchased from EMD. HEPES, free acid, was purchased from OmniPur. Vulcan carbon was a kind gift from the Cabot Corporation. Deionized water (18 $\mathrm{M} \Omega$ ) was used to prepare all solutions. 
Artificial saliva solution $\left(0.70 \mathrm{mM} \mathrm{CaCl}_{2}, 0.427 \mathrm{mM} \mathrm{MgCl}_{2}, 4 \mathrm{mM} \mathrm{NaH}{ }_{2} \mathrm{PO}_{4}, 20 \mathrm{mM}\right.$ HEPES, $30 \mathrm{mM} \mathrm{KCl}$ ) was freshly prepared and stored at room temperature. ${ }^{28}$ The $\mathrm{pH}$ was adjusted to $4.5,6$, and 7.2 by additions of $\mathrm{NaOH}$ or $\mathrm{HCl}$.

\section{Instrumentation}

Electrochemical measurements were performed with a CHI model 920D bipotentiostat and an SECM instrument (CH Instruments, Austin, TX, USA). An Ag/ $\mathrm{AgCl}$ reference electrode and a $0.5 \mathrm{~mm}$ Pt counter electrode were used in all electrochemical experiments. All potentiometric measurements were performed with a high impedance potentiometer (Lawson Labs, Malvern, PA, USA and EA Instruments, Middlesex, UK).

\section{Fabrication of pH-sensing dual SECM tip}

A theta pipette was used to fabricate the dual-tip UME. The pipette was pulled with a pipette puller (Sutter Instruments, Novato, California, USA), and $1.5 \mathrm{~cm}$ long, $25 \mu \mathrm{m}$ diameter platinum wires were inserted into each cavity of the pipette before sealing. Platinum wires were connected to copper wires by conductive silver epoxy. The electrode surface was then polished on a polishing pad via the successive use of $1.0,0.3$, and $0.05 \mu \mathrm{m}$ alumina powder. The electrode was tested by cyclic voltammetry in a $1 \mathrm{mM}$ ferrocene methanol and $0.1 \mathrm{M}$ $\mathrm{KCl}$ solution. The electrode was further characterized by running probe approach curves (with each electrode, independently) above an insulating substrate in the presence of ferrocene methanol solution. The $\mathrm{pH}$ sensor was fabricated by electrochemically depositing polyaniline onto one of the two Pt surfaces by cycling the potential from -0.2 to $1.0 \mathrm{~V}$ ( $\mathrm{vs}$. $\mathrm{Ag} / \mathrm{AgCl}$ reference) in $0.1 \mathrm{M}$ aniline and $1 \mathrm{M} \mathrm{HCl}$ at $100 \mathrm{mV} / \mathrm{s}$ for 50 cycles. A schematic of the dual-tip $\mathrm{pH}$ sensor is shown in Figure 2A (left). $\mathrm{pH}$ calibration was performed with a high impedance potentiometer at room temperature $\left(23^{\circ} \mathrm{C}\right)$ by addition of $1 \mathrm{M} \mathrm{NaOH}$ to artificial saliva to bring the $\mathrm{pH}$ from 4.5 to 8 .

\section{Fabrication of calcium-sensing SECM tip}

A cocktail of the following composition was prepared in THF (w/w): ETH 129 (5\%), KTPIB (2\%), NPOE (30 \%), PVC (3\%), and Vulcan carbon powder (60\%). The composition was mixed thoroughly with a glass rod in a watch glass and an additional $40 \%$ of NPOE was added to obtain a pasty consistency. The resulting paste was then packed into the back of a pulled borosilicate capillary tube (o.d. $1.5 \mathrm{~mm}$; i.d. $0.86 \mathrm{~mm}$ ). The pulled capillary tubes were polished to obtain an internal tip diameter of $25 \mu \mathrm{m}$ and an RG (ratio of glass insulation diameter to electrode diameter) $<4$. The cocktail was pushed with a copper wire with pressure until the cocktail squeezed out of the capillary tip. To make the backside contact, the back end of capillary was filled with a 2.6 (w/w \%) of Vulcan carbon in DOS. A copper wire was subsequently inserted from the back and glued with epoxy. The electrode was wiped with lens paper to obtain a clean and smooth surface and later cured/soaked in artificial saliva for at least $12 \mathrm{~h}$ before use. A schematic of the $\mathrm{Ca}^{2+}$-ISME is shown in Figure 2A (right). 


\section{Testing the potentiometric and amperometric function of the $\mathrm{Ca}^{2+}$-ISME}

The sensors were calibrated by using the standard addition method in artificial saliva and in $0.1 \mathrm{M} \mathrm{KCl}$ solution respectively. The $\mathrm{pH}$-dependent potentiometric response of the sensors was also tested in HEPES buffer and artificial saliva solution. Later, the sensors were calibrated in potentiometric mode separately in the presence of $1 \mathrm{mM}$ of RuHex, ferrocene methanol, and ferrocyanide, as well as in varying concentrations of RuHex solution, to determine the effect of redox active molecules on potentiometric $\mathrm{Ca}^{2+}$ sensing.

The amperometric response was characterized by calibrating the sensors with artificial saliva solution that contained hexaammineruthenium (RuHex) by square wave voltammetry and the constant potential method. The effect of the amperometric method, i.e. applying potential to the $\mathrm{Ca}^{2+}$-ISME, on the potentiometric capability of the sensor was measured in the presence of both calcium ions and redox molecules. A potential was applied to the sensor for $1 \mathrm{~h}$ and precalibration and postcalibration curves were obtained to test the effect of passing current on the potentiometric response of $\mathrm{Ca}^{2+}$-ISME. In addition, the sensors were calibrated by the addition of $\mathrm{Ca}^{2+}$ standards in artificial saliva solution before each SECM experiment. We used the calibrated sensors with $\mathrm{RG}<4$ to perform amperometric approach curves on the surface of the exposed BAG, as well as on Kapton tape (Figure 2B). The experimental approach curves were later fit with the theoretical approach curves to determine the tip-substrate distance. ${ }^{6}$

\section{Preparation of dental composite samples}

BAG powder was synthesized by using the sol-gel method as previously described. ${ }^{29,30}$ The BAG disks were prepared by pressing the BAG powder into steel molds in a universal testing machine. The typical resin composite formulation was as follows (mol \%): 65\% Si, $31 \% \mathrm{Ca}$, and $4 \% \mathrm{P}$ in the form of their elemental oxides. These composites were pressed at 6,000 PSI into $12.5 \mathrm{~mm}$ discs and cured within plastic molds by using an LED dental curing unit with $20 \mathrm{~mJ} / \mathrm{cm}^{2}$ total energy to ensure adequate cure. BAG disk composites were polished with rough sandpaper (120 grit) prior to each use. Kapton tape was used to cover the composite surface, leaving an exposed surface of $1.6 \mathrm{~mm}$ diameter when necessary (Figure 2B).

\section{SECM experiments with dental composites}

The BAG disk was secured inside a $30 \mathrm{~mm}$ petri dish and attached to the SECM stage (Figure 2B). The BAG or the SECM substrate tilt over the distance of 5,000 $\mu \mathrm{m}$ was fixed by using a $25 \mu \mathrm{m}$ diameter Pt-UME before all $\mathrm{pH}$ and $\mathrm{Ca}^{2+}$ mapping. The Pt-UME was then replaced by a $\mathrm{Ca}^{2+}$-ISME and the probe approach curves were performed in the presence of $1 \mathrm{mM}$ potassium ferrocyanide solution to determine the probe-substrate distance. The redoxcontaining artificial saliva solution was later replaced with $15 \mathrm{~mL}$ artificial saliva solution at the designated $\mathrm{pH}$ before potentiometric measurements were recorded. Probe scans in the $\mathrm{z}$ direction began at 2,020 $\mu \mathrm{m}$ above the BAG surface and approached at a speed of $3 \mu \mathrm{m} / \mathrm{s}$. Xdirection scans of 3,000-5,000 $\mu \mathrm{m}$ were performed at a constant distance of 150-820 $\mu \mathrm{m}$ above the substrate. SECM images were taken at $50 \mu \mathrm{m} / \mathrm{s}$ at heights of 100, 200, and 1,000 $\mu \mathrm{m}$ above the BAG surface. A $\mathrm{pH}$ sensor and a $\mathrm{Ca}^{2+}$-ISME were used as an SECM probe to map $\mathrm{pH}$ and $\mathrm{Ca}^{2+}$ ions, respectively, in separate experiments. 


\section{Bulk pH and calcium ion measurements}

Composites were submerged in $15 \mathrm{~mL}$ of artificial saliva solution at a designated $\mathrm{pH}$ and left undisturbed at room temperature. The supernatant was removed, mixed thoroughly, and tested at various times by using a glass $\mathrm{pH}$ probe. Similarly, the bulk concentrations of free calcium ions were measured by the $\mathrm{Ca}^{2+}{ }_{-}$ISME. BAG substrate was submerged for $4 \mathrm{~h}$ in artificial saliva solution of different $\mathrm{pH}$ values between 4.5 and 7.2 and then supernatants were collected to determine the $\mathrm{Ca}^{2+}$ present in the solution.

\section{RESULTS AND DISCUSSION}

\section{Electrochemical characterization of dual pH-sensing electrode}

The dual electrode comprised two $25 \mu \mathrm{m}$ Pt electrodes: one for amperometry (bare $\mathrm{Pt}$ electrode) and the other for potentiometry ( $\mathrm{pH}$ sensor). Cyclic voltammetry and probe approach curve experiments using bare Pt electrodes showed no appreciable difference at the electrode surfaces (Figure S1A). The approach curve was later fit with the theoretical curve, ${ }^{6}$ as shown in Figure S1B. The potentiometric $\mathrm{pH}$-sensing electrode $(25 \mu \mathrm{m}$ polyaniline modified Pt electrode) was calibrated by the standard addition method, as shown in Figure S2. Only sensors with a slope of $-59 \pm 2 \mathrm{mV} / \mathrm{pH}$ were used for further SECM studies. The bare $25 \mu \mathrm{m}$ Pt electrode was used for performing approach curves to fix the tip-substrate distance.

\section{Electrochemical characterization of $\mathrm{Ca}^{2+}+$ ISME}

The potentiometric response of the $\mathrm{Ca}^{2+}$-ISME and the corresponding calibration curve are shown in Figures S3A and 3A. The sensor shows a broad dynamic range response over the concentration range of $5 \mu \mathrm{M}$ to $200 \mathrm{mM}$ with a slope of $28 \pm 2 \mathrm{mV} / \log \left[\mathrm{a}_{\mathrm{Ca} 2+}\right]$. The limit of

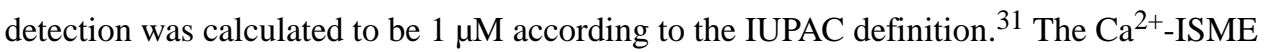
also showed a very fast response time of $\sim 0.2 \mathrm{~s}$ (Figure 3B) in the presence of $500 \mu \mathrm{M}$ of calcium ions and thus can be used as a scanning probe for SECM experiments.

The $\mathrm{pH}$ interference test was conducted both in $0.1 \mathrm{M} \mathrm{KCl}$ and in artificial saliva solution with a constant concentration of $10 \mu \mathrm{M} \mathrm{Ca}^{2+}$ (Figure 3C). The $\mathrm{pH}$ was varied from 4.5 to 7.2 and the potential response of the $\mathrm{Ca}^{2+}$-ISME was recorded. The $\mathrm{Ca}^{2+}$-mediated potentiometric signal was constant from $\mathrm{pH} 4.5$ to 6.8 , followed by a small $2 \mathrm{mV}$ change in the $\mathrm{pH}$ range of 6.8 to 7.2 for a $0.1 \mathrm{M} \mathrm{KCl}$ and $10 \mathrm{mM}$ HEPES solution. A similar constant potential response was observed for artificial saliva solution ( $\mathrm{pH} 4.5$ to 6.2), except a potential variation of $4 \mathrm{mV}$ was recorded from $\mathrm{pH} 6.2$ to 7.2. This small change in potential beyond a near neutral $\mathrm{pH}$ value is due to the change in solubility of the $10 \mu \mathrm{M}$ free $\mathrm{Ca}^{2+}$ in the presence of artificial saliva solution containing phosphate ions. Further tests were done to record the response of $\mathrm{Ca}^{2+}$-ISME in increasing initial concentrations of $\mathrm{Ca}^{2+}$ (Figure 3D). These tests confirm the differential solubility of $\mathrm{Ca}^{2+}$ with changing $\mathrm{pH}$ and show that the $\mathrm{Ca}^{2+}$-ISME was unresponsive to a change in $\mathrm{pH}$. This observation is significant, as we could use this sensor for SECM experiments to map the $\left[\mathrm{Ca}^{2+}\right]$ above the BAG surface, where the change in calcium ion concentration is accompanied by a change in $\mathrm{pH}$. 
Figure 4A shows the calibration curve of the calcium ions in the presence of $1 \mathrm{mM}$ ferrocene methanol, RuHex and ferrocyanide in artificial saliva solution. The $\mathrm{Ca}^{2+}{ }^{2}$-ISME shows Nernstian response in the presence of all of the above-mentioned redox species, as well as before and after applying the potential to the electrode (Figure S3B). However, the presence of ferricyanide redox molecules affects the response of $\mathrm{Ca}^{2+}-$ ISME in the low $\mathrm{Ca}^{2+}$ concentration range $(\leq 0.01 \mathrm{mM})$ but still shows the Nernstian slope in the higher $\mathrm{Ca}^{2+}$ concentration range ( 0.1 to $1 \mathrm{mM})$. The non-specific adsorption of ferricyanide on the sensor surface might contribute to such behavior. The absolute potential shift for various calibration curves shown in Figures 4A is because of the use of different electrodes. In addition, the sensor showed no change in potential in presence of increasing amount of RuHex confirming it's insensitivity towards the redox molecules. (Figure 4B).

The selectivity of the $\mathrm{Ca}^{2+}$-ISME was tested by the matched potential method. A solution of $0.1 \mathrm{M} \mathrm{KCl}$ at $\mathrm{pH} 4.5$ with a concentration of $5 \mu \mathrm{M} \mathrm{Ca}^{2+}$ ions was chosen as the starting point. The response of the $\mathrm{Ca}^{2+}$-ISME to a small increment from $5 \mu \mathrm{M} \mathrm{Ca}^{2+}$ to $6 \mu \mathrm{M} \mathrm{Ca}^{2+}$ was measured as $3 \mathrm{mV}$. Later, the concentration of the interfering ion was increased on top of the $5 \mu \mathrm{M} \mathrm{Ca}^{2+}$ and the response of the $\mathrm{Ca}^{2+}$-ISME was recorded. The selectivity coefficient was determined by $K_{p o t}=\left(\mathbf{a}_{c a^{2+}}-\mathbf{a}^{\prime} c a^{2+}\right) / \mathbf{a}_{A}$, where $\mathbf{a}_{c a^{2+}}, \mathbf{a}_{c a^{\prime}}{ }^{2+}$ are the activities of $5 \mu \mathrm{M} \mathrm{Ca}^{2+}$ to $6 \mu \mathrm{M} \mathrm{Ca}^{2+}$, respectively, and $\mathbf{a}_{A}$ is the activity of the interfering ion, which showed an equivalent response of $3 \mathrm{mV}$. Table 1 shows the selectivity against common interferents in artificial saliva. The selectivity coefficients of this $\mathrm{Ca}^{2+}$-ISME are reported as $\log \mathrm{K}_{\mathrm{Ca}^{2+}, \mathrm{A}}=-5.88,-5.54$, and -6.31 for $\mathrm{Mg}^{2+}, \mathrm{Na}^{+}$, and $\mathrm{K}^{+}$, respectively, in $0.1 \mathrm{M} \mathrm{KCl}$ at $\mathrm{pH} 4.5$ (Table 1). The selectivity coefficients were also measured by using the fixed interference method. A fixed concentration of the interfering ion and $10 \mathrm{mM}$ HEPES was chosen as the background solution and calcium ions were added to increase the concentration from $1 \mathrm{nM}$ to $100 \mathrm{mM}$. The calculated selectivity coefficients for $\mathrm{Ca}^{2+}{ }_{-}$ISME is comparable to earlier reports $\left(\sim \log \mathrm{K}_{\mathrm{Ca}^{2+}{ }_{,} \mathrm{A}}=-4.5\right.$ to -6.0$) .{ }^{32,33,34}$ The limit of detection of the calcium ions was used to calculate the selectivity as $K_{C a \text {,int }}^{\mathrm{pot}}=a_{C a} / a_{\mathrm{int}}^{\left(\frac{z_{C a}}{z_{\text {int }}}\right)}$, where $\mathrm{z}$ represents charge of the corresponding species.

After potentiometric characterization, we tested whether the $\mathrm{Ca}^{2+}$-ISME could also be used as an SECM tip by obtaining a negative feedback approach curve on an insulator. Hence, the calibration curve using square wave voltammetry and the constant potential method were first performed by using RuHex as a redox mediator to obtain a linear relationship (Figure $5 \mathrm{~A}$ and $5 \mathrm{~B}$ ) between the redox couple concentration and the tip current. Subsequently, a cyclic voltammetry was obtained (Figure 5C) and a negative feedback approach curve was recorded by using RuHex as a redox mediator and was fit with the theoretical approach curve (Figure 5D). The good fit of the experimental approach curve indicates that this $\mathrm{Ca}^{2+}$ ISME could be used in future SECM experiments.

\section{pH profile above BAG using SECM}

Figure 6A shows the schematic representation of the $\mathrm{pH}$ profile produced by BAG in an acidic solution ( $\mathrm{pH} 4.5)$. The local $\mathrm{pH}$ remained relatively constant when more basic $(\mathrm{pH} 6.0$ and 7.2) artificial saliva solution was added to the BAG sample dish. The z-direction scan 
(Figure 6B) shows the neutralization zone extending $600 \mu \mathrm{m}$ above the surface for the acidic solution ( $\mathrm{pH} 4.5$ ) and the bulk solution remaining constant at $\mathrm{pH}$ 4.5. A similar neutralization zone was observed during $\mathrm{x}$-scans over the BAG surface at various heights (Figure 6C) in the same acidic solution (pH 4.5). Figure 6D shows the $\mathrm{x}$-scans over the BAG surface at same height $(\mathrm{z}=220 \mu \mathrm{m})$ for $\mathrm{pH} 4.5,6.0$, and 7.2 solutions. Figure $6 \mathrm{C}$ also confirms that the BAG substrate was able to neutralize the local $\mathrm{pH}$. However, little to no neutralization zone was observed in the presence of solution at $\mathrm{pH} 6.0$ and 7.2, as shown in Figures 6B and 6D. To estimate the extension of this neutralization zone in the $x-y$ plane, we obtained constant height $\mathrm{pH}$ mapping (Figure 7) at a distance of 100 and 1,000 $\mu \mathrm{m}$ above the BAG surface.

\section{Calcium ion profile above the BAG using SECM}

$\mathrm{Ca}^{2+}$-ISME was used to map the $\mathrm{pH}$-dependent calcium ion release from BAG, as shown in Figure 8A, B, and C. The z-direction calcium ion release profiles in the presence of various $\mathrm{pH}$ solutions ( $\mathrm{pH} 4.5,6.0,7.2)$ are shown in Figure 8A. The z-direction scans show that the calcium ion concentrations remained constant in bulk solution, 1,000 $\mu \mathrm{m}$ from the surface of the BAG. The $\mathrm{Ca}^{2+}$ concentrations in artificial saliva solution increased by $0.7 \mathrm{mM}$ in $\mathrm{pH}$ 4.5, by $0.3 \mathrm{mM}$ in $\mathrm{pH} 6.0$, and by $0.02 \mathrm{mM}$ in $\mathrm{pH} 7.2$, indicating that the calcium ions released from the BAG are $\mathrm{pH}$ dependent. Figure $8 \mathrm{~B}$ shows $\mathrm{x}$-scans at different heights above the $\mathrm{BAG}$ in the presence of an artificial saliva solution at $\mathrm{pH} 4.5$. The $\mathrm{x}$-scans show that the concentration of the $\mathrm{Ca}^{2+}$ ions increased over the exposed BAG and there was a more pronounced effect in the $\mathrm{x}$-scans taken closer to the surface. $\mathrm{A} \mathrm{Ca}^{2+}$ profile image was obtained with artificial saliva at $\mathrm{pH} 4.5$ at a fixed height of $200 \mu \mathrm{m}$ above the BAG, as shown in Figure 8C. The 3-D image shows that the calcium ion concentration increased to $1.2 \mathrm{mM}$ at $200 \mu \mathrm{m}$ above the BAG. The calibrations obtained before and after applying the potential to the electrode are reported in Figure S3B. The data from Figure S3B shows that the change in slope is less than $1 \mathrm{mV} / \log \left[\mathrm{Ca}^{2+}\right]$ before and after applying potential to the $\mathrm{Ca}^{2+}$-ISME. Since the data over the BAG were collected after positioning the tip in amperometric mode, the calcium ion concentrations during the SECM experiments were calculated from a postSECM experiment calibration curve for the appropriate $\mathrm{pH}$ solution.

\section{Correlation of $\mathrm{pH}$ and calcium ion profile above the BAG surface}

The main function of the BAG material is to neutralize the local environment when it is exposed to a low $\mathrm{pH}$ solution $(\mathrm{pH}<5.5)$. The calcium oxide present inside the BAG reacts with the acidic solution, neutralizing the local $\mathrm{pH}$ and subsequently releasing $\mathrm{Ca}^{2+}$. Our results (Figures 6 and 7 and Table 2) show that the BAG is able to neutralize the local pH to $6.0 \pm 0.3$ even though the bulk solution remains at $\mathrm{pH} 4.5$. This leads to the release of calcium ions, which can then react with the phosphates that are present in the buffer and precipitate out of the solution. However, precipitation of calcium phosphate highly depends on the $\mathrm{pH}$ of the solution. Hence, when we map the calcium ions in solutions of $\mathrm{pH} 4.5$, we are essentially mapping the change in the solubility of calcium phosphate, along with the change in the $\mathrm{pH}$ profile (i.e. $\mathrm{pH} 6.0$ to 4.5 , or the amount of free calcium ions in equilibrium with calcium phosphate at a particular $\mathrm{pH}$ ). It is for this reason that we observed the decrease in calcium ions in close proximity (less than $50 \mu \mathrm{m}$ distance) of the BAG, where the local $\mathrm{pH}$ was observed to be 6.0. As the $\mathrm{pH}$ decreased with the increasing distance 
from the BAG surface (Figure 6B), the amount of free calcium ions changed from $1.4 \mathrm{mM}$ (20 $\mu \mathrm{m}$ above BAG) to $0.7 \mathrm{mM}$ bulk ( 1,000 $\mu \mathrm{m}$ above BAG) (see Figure 8A). As reported in Table 2, when acidic artificial saliva of $\mathrm{pH} 4.5$ was added to BAG surface, the local $\mathrm{pH}$ changed from 4.5 to 6.0 whereas the local $\left[\mathrm{Ca}^{2+}\right]$ changed from 0.7 to $1.4 \mathrm{mM}$. i.e. a change in $\left[\mathrm{H}^{+}\right]$of $31 \mu \mathrm{M}$ is accompanied by change in $\left[\mathrm{Ca}^{2+}\right]$ of $700 \mu \mathrm{M}$. According to the reaction mechanism (considering same volume), $\left[\mathrm{H}^{+}\right]:\left[\mathrm{Ca}^{2+}\right]$ should be in 1:0.5 ratio in contrast to our observed value of $1: 23$, which indicates a significantly higher concentration of free $\mathrm{Ca}^{2+}$ ions. This is admissible if we consider the initial contact of acidic solution of $\mathrm{pH} 4.5$ and the subsequent burst of release of $\mathrm{Ca}^{2+}$ from BAG surface. In addition, the solubility of $\mathrm{Ca}^{2+}$ increases as the $\mathrm{pH}$ becomes more acidic from the surface to bulk above BAG until the system came to a dynamic equilibrium. Also, the buffering capacity of the artificial saliva solution becomes more dominant as the $\mathrm{pH}$ of the solution becomes more basic (pH 6.2) close to the BAG surface. This phenomenon was confirmed by the bulk free calcium ions experiment done in artificial saliva solution (see figure 3D). As expected, we observed a lower calcium ion concentration profile of $0.9 \mathrm{mM}$ to $0.6 \mathrm{mM}(20 \mu \mathrm{m}$ to $1,000 \mu \mathrm{m})$ in the presence of a solution at $\mathrm{pH}$ 6.0. In Figures 6B and 8A, as expected, no such neutralization phenomenon occurred and the free calcium ion profile was not observed when a neutral solution of $\mathrm{pH} 7.2$ was added to the BAG. The bulk ( $500 \mu \mathrm{m}$ above the BAG surface) concentrations of the calcium and proton ions did not change after $4 \mathrm{~h}$ of exposure of the artificial saliva at $\mathrm{pH} 4.5,6$, and 7.2, as shown in Table 2. This quantitative mapping of $\mathrm{pH}$ and calcium ions will aid us in predicting the local chemical environment above BAG and thus will help us to optimize the composition of dental materials.

\section{CONCLUSIONS}

The newly developed fast response carbon based $\mathrm{Ca}^{2+}$-ISME and dual electrode $\mathrm{pH}$ sensors allowed us to quantitatively map the neutralizing capacity of BAG while estimating the amount of calcium ions that it releases. Testing revealed that exposure of BAG to acidic conditions ( $\mathrm{pH} 4.5)$ results in a change of local $\mathrm{pH}$ and $\left[\mathrm{Ca}^{2+}\right](6.0$ and $1.5 \mathrm{mM}$, respectively) extending $500 \mu \mathrm{m}$ above the BAG surface. The release and reprecipitation of the $\mathrm{Ca}^{2+}$ ions from the smart dental composite provides a means to neutralize acidic $\mathrm{pH}$ while reducing the erosion of material, thereby enhancing the overall longevity of the filling. The ability to measure this local $\mathrm{pH}$ and calcium ion concentration will open opportunities to characterize the ion-releasing capacity of new dental materials and their effects on the surrounding in vivo oral environment.

\section{Supplementary Material}

Refer to Web version on PubMed Central for supplementary material.

\section{Acknowledgments}

Dr. D. Koley (Grant \# 1R21DE025370-01) and Dr. J. Ferracane (Grant \# 5R01 DE021372) acknowledge the support from the National Institutes of Dental and Craniofacial Research (NIDCR). Dr. D. Koley also gratefully acknowledges the financial support from the Oregon State University start-up fund. 


\section{REFERENCES}

1. Farooq I, Imran Z, Farooq U, Leghari A, Ali H. Bioactive Glass: A Material for the Future. World Journal of Dentistry. 2012; 3:199-201.

2. Moreau JL, Sun L, Chow LC, Xu HHK. J. Biomed. Mater. Res. B. Appl. Biomater. 2011; 98:80-88. [PubMed: 21504057]

3. Jones JR. Acta Biomater. 2013; 9:4457-4486. [PubMed: 22922331]

4. Ferracane JL. Dent. Mater. 2013; 29:51-58. [PubMed: 22809582]

5. Ferracane JL. Dent. Mater. 2011; 27:29-38. [PubMed: 21093034]

6. Bard, AJ.; Mirkin, MV., editors. Scanning Electrochemical Microscopy, Second Edition. CRC Press; 2012.

7. Mirkin MV, Nogala W, Velmurugan J, Wang Y. Phys. Chem. Chem. Phys. 2011; 13:21196-21212. [PubMed: 22031463]

8. Sun P, Laforge FO, Mirkin MV. Phys. Chem. Chem. Phys. 2007; 9:802-823. [PubMed: 17287874]

9. Amemiya S, Bard AJ, Fan F-RF, Mirkin MV, Unwin PR. Annu. Rev. Anal. Chem. 2008; 1:95-131. 10. Wei C, Bard AJ, Mirkin MV. J. Phys. Chem. 1995; 99:16033-16042.

11. Yamada H, Haraguchi D, Yasunaga K. Anal. Chem. 2014; 86:8547-8552. [PubMed: 25109344]

12. Izquierdo J, Kiss a, Santana JJ, Nagy L, Bitter I, Isaacs HS, Nagy G, Souto RM. J. Electrochem. Soc. 2013; 160:C451-C459.

13. Wang Y, Kececi K, Velmurugan J, Mirkin MV. Chem. Sci. 2013; 4:3606.

14. Wei C, Bard AJ, Kapui I, Nagy G, Toth K. Anal. Chem. 1996; 68:2651-2655. [PubMed: 21619212]

15. Etienne M, Dierkes P, Erichsen T, Schuhmann W, Fritsch I. Electroanalysis. 2007; 19:318-323.

16. Yamada H, Ikuta Y, Koike T, Matsue T. Chem. Lett. 2008; 37:392-393.

17. Wipf D, Ge F, Spaine T, Baur J. Anal. Chem. 2000; 72:4921-4927. [PubMed: 11055710]

18. Zhang X, Ogorevc B, Wang J. Anal. Chim. Acta. 2002; 452:1-10.

19. Michalska A, Konopka A, Maj-Zurawska M. Anal. Chem. 2003; 75:141-144. [PubMed: 12530830]

20. Konopka A, Sokalski T, Michalska A, Lewenstam A, Maj-Zurawska M. Anal. Chem. 2004; 76:6410-6418. [PubMed: 15516135]

21. Lindfors T, Ivaska A. Anal. Chim. Acta. 2000; 404:101-110.

22. Lindfors T, Ivaska A. Anal. Chim. Acta. 2000; 404:111-119.

23. Michalska A. Electroanalysis. 2005; 17:400-407.

24. Wang S-H, Chou T-C, Liu C-C. Sensors Actuators B Chem. 2003; 96:709-716.

25. Etienne M, Schulte A, Mann S, Jordan G, Dietzel ID, Schuhmann W. Anal. Chem. 2004; 76:36823688. [PubMed: 15228341]

26. Horrocks BR, Mirkin MV, Pierce DT, Bard AJ, Nagy G, Toth K. Anal. Chem. 1993; 65:12131224.

27. Csoka B, Mekhalif Z. Electrochim. Acta. 2009; 54:3225-3232.

28. Ionta FQ, Mendonca FL, de Oliveira GC, de Alencar CRB, Honorio HM, Magalhaes AC, Rios D. J. Dent. 2014; 42:175-179. [PubMed: 24269764]

29. Mitchell JC, Musanje L, Ferracane JL. Dent. Mater. 2011; 27:386-393. [PubMed: 21195473]

30. Khvostenko D, Mitchell JC, Hilton TJ, Ferracane JL, Kruzic JJ. Dent. Mater. 2013; 29:1139-1148. [PubMed: 24050766]

31. Wilkinson, ADM.; A, editors. IUPAC. Compendium of Chemical Terminology, 2nd ed. (the "Gold Book”). Oxford: Blackwell Scientific Publications; 1997.

32. Bedlechowicz I, Maj-Żurawska M, Sokalski T, Hulanicki A. J. Electroanal. Chem. 2002; 537:111118.

33. Anker P, Wieland E, Ammann D, Dohner RE, Asper R, Simon W. Anal. Chem. 1981; 53:19701974. [PubMed: 7316204]

34. Sokalski T, Maj-Żurawska M, Hulanicki A. Mikrochim. Acta. 1991; 103:285-291. 


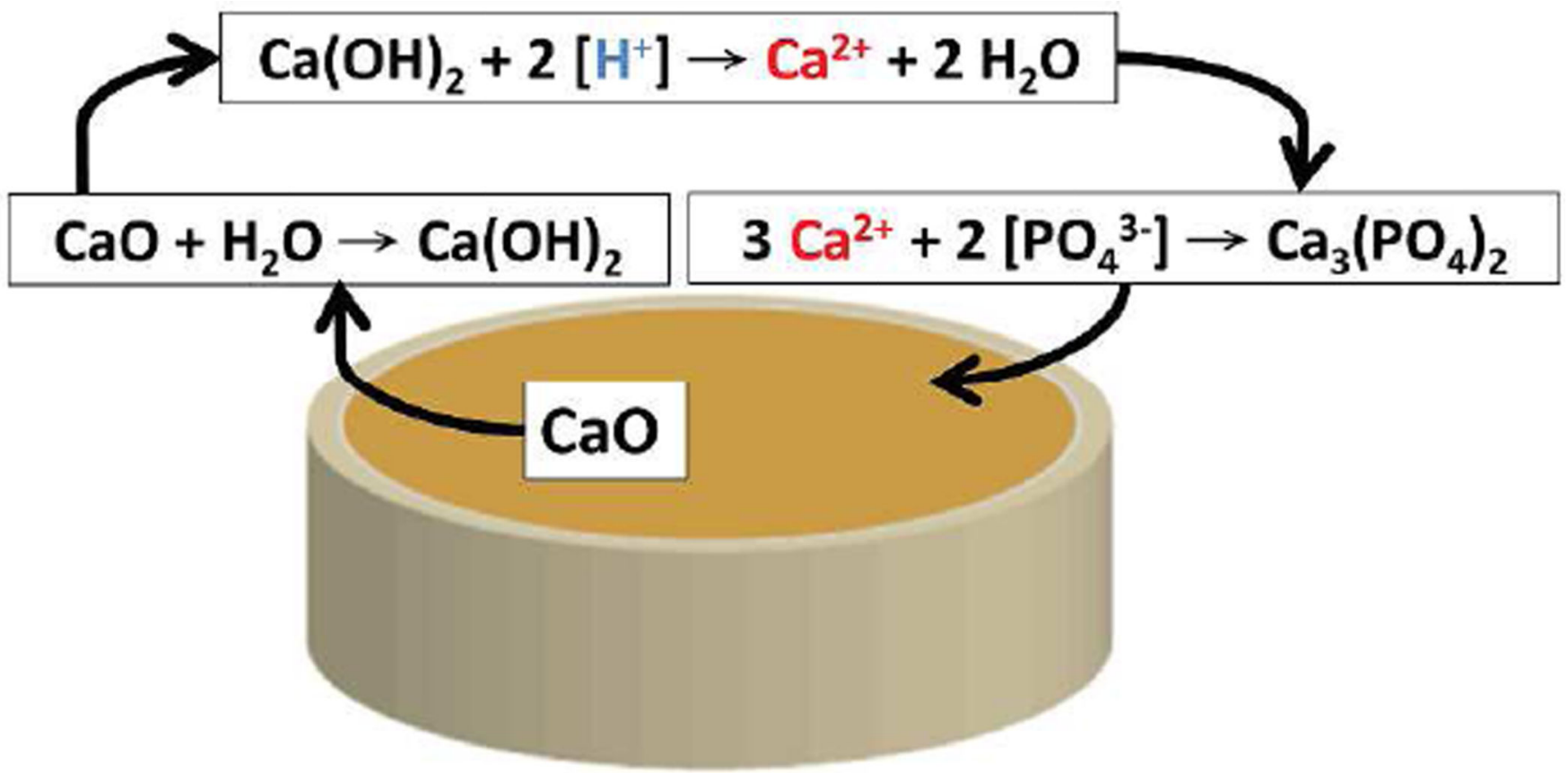

Figure 1.

Schematic diagram of $\mathrm{pH}$-dependent calcium ion release from bioactive glass (BAG) when exposed to acidic conditions (pH 6.0 or lower). 
$\begin{array}{lll}\text { A Dual electrode } & \text { Dual function } & \text { B }\end{array}$ pH sensor

$\mathrm{Ca}^{2+}-$ ISME
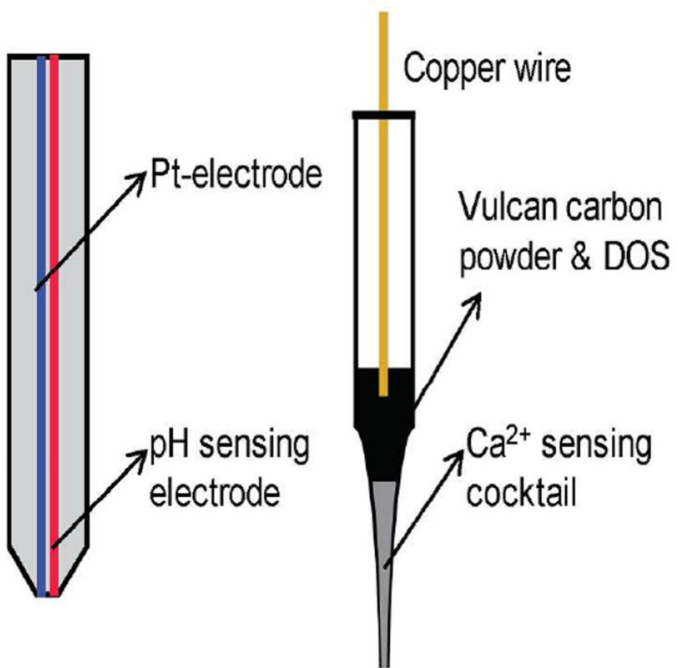

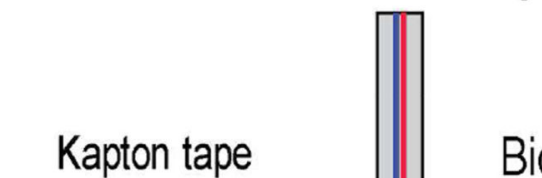

Bioactive glass

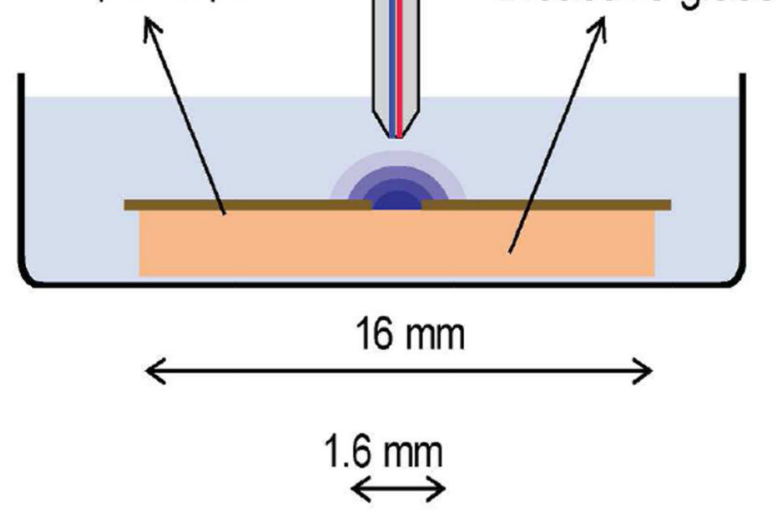

Figure 2.

(A) Schematic representation of the (left) dual-electrode $\mathrm{pH}$ sensor $(25 \mu \mathrm{m}$ diameter Pt wire for each tip) and (right) 25-30 $\mu \mathrm{m}$ diameter carbon based solid-state calcium ion-selective microelectrode. (B) SECM-BAG experimental setup. A $0.5 \mathrm{~mm}$ Pt wire and an $\mathrm{Ag} / \mathrm{AgCl}$ were used as counter and reference electrodes, respectively (not shown). 

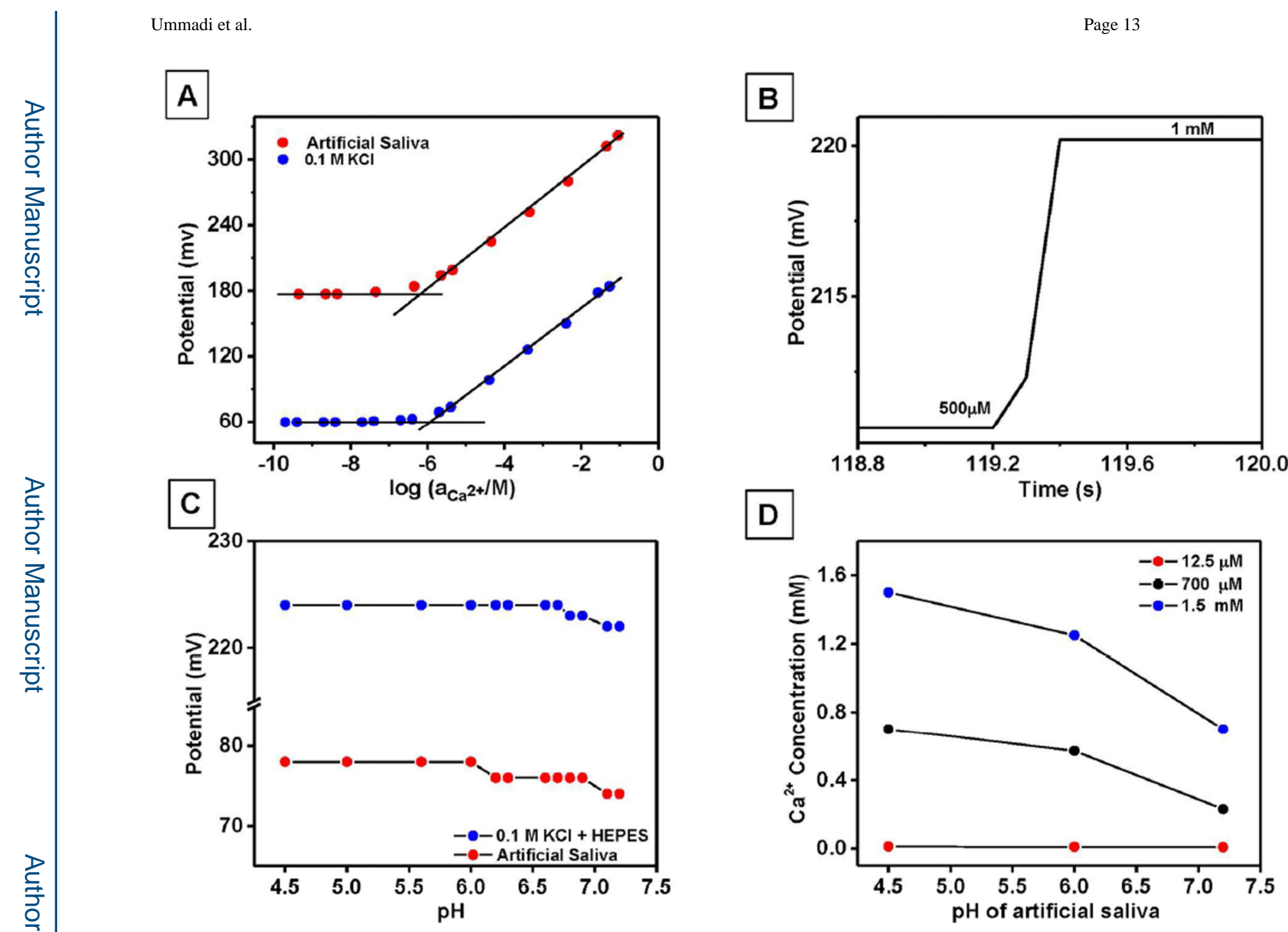

D

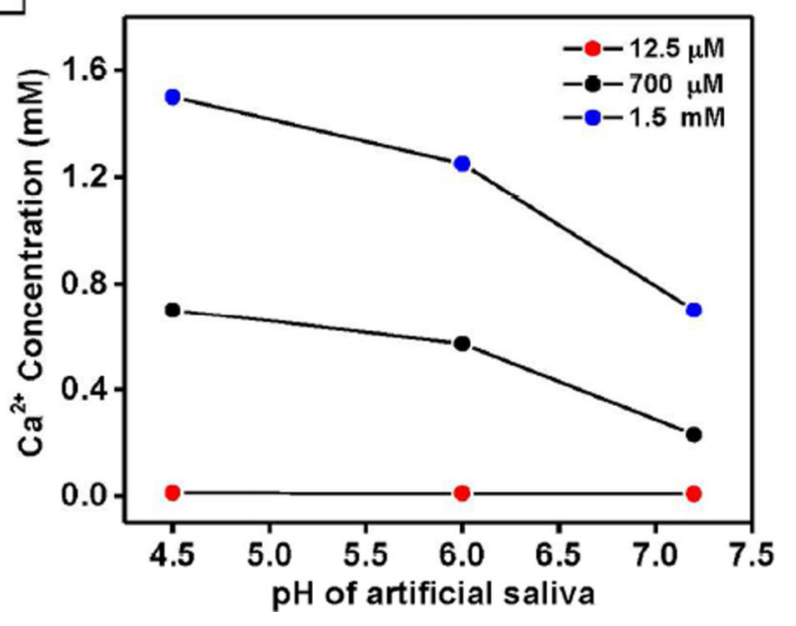

Figure 3.

Potentiometric characterization of the $\mathrm{Ca}^{2+}$-ISME. (A) Calibration curves of all solid-state $\mathrm{Ca}^{2+}$ sensors in artificial saliva (slope $=28 \mathrm{mV} / \log \mathrm{a}_{\mathrm{Ca}}{ }^{2+} / \mathrm{M}$ ) and $0.1 \mathrm{M} \mathrm{KCl}$ (slope $=27$ $\mathrm{mV} / \log \mathrm{a}_{\mathrm{Ca}}{ }^{2+} / \mathrm{M}$ ) solutions at $\mathrm{pH} 4.5$ with no initial $\mathrm{Ca}^{2+}$. (B) Potentiometric response time of the sensor in the presence of $500 \mu \mathrm{M} \mathrm{Ca}^{2+}$. The response time was 0.17 seconds. (C) Potential response of the sensor with a change in $\mathrm{pH}$ from 4.5 to 7.2 in artificial saliva (red) and $0.1 \mathrm{M} \mathrm{KCl}$ and $10 \mathrm{mM}$ HEPES (blue) with a constant $\mathrm{Ca}^{2+}$ concentration of $10 \mu \mathrm{M}$. (D) $\mathrm{Ca}^{2+}$ solubility change with change in $\mathrm{pH}$ in artificial saliva with different initial $\mathrm{Ca}^{2+}$ concentrations. 
A

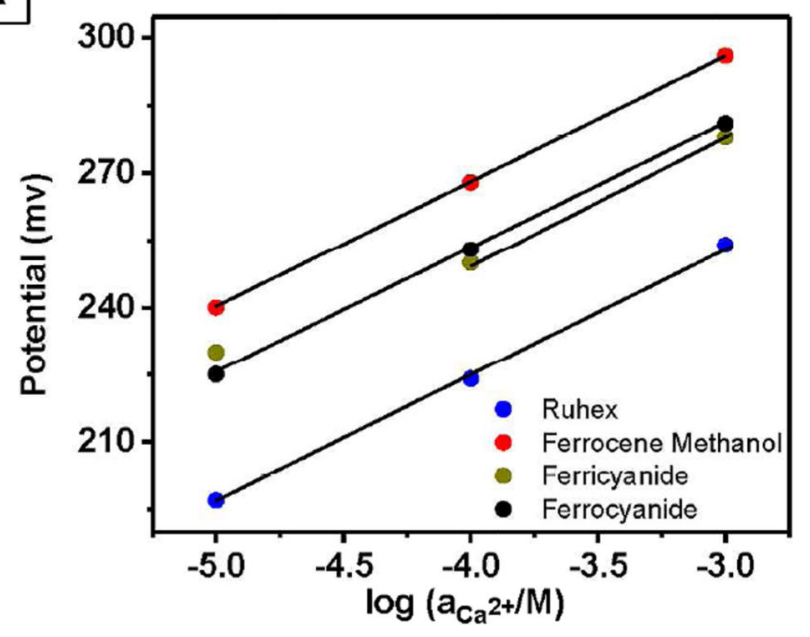

B

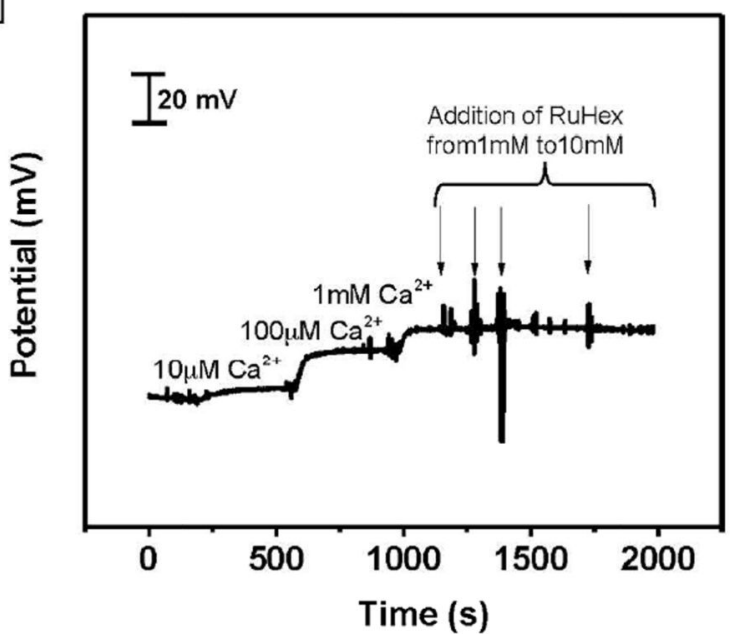

Figure 4.

(A) Potentiometric calibration curves of $\mathrm{Ca}^{2+}$-ISME in the presence of $1 \mathrm{mM}$ each of RuHex, ferrocene methanol, ferricyanide and ferrocyanide. (B) Potentiometric response of $\mathrm{Ca}^{2+}$-ISME, in the presence of $1 \mathrm{mM}$ calcium ions, to increments in concentrations of redox molecules. 

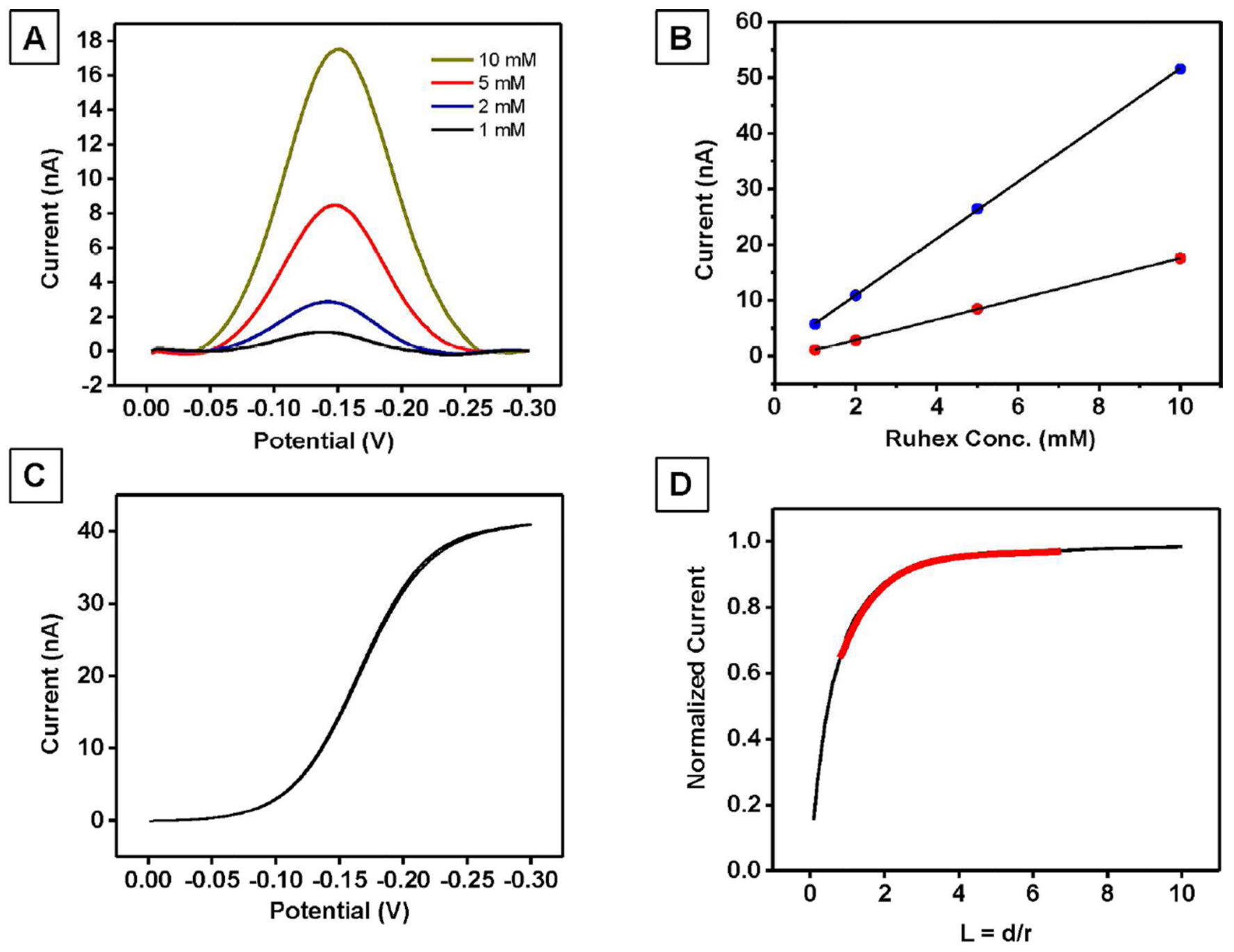

Figure 5.

Amperometric characterization of $\mathrm{Ca}^{2+}$-ISME in artificial saliva solution ( $\mathrm{pH} 4.5$ ). (A) Square wave voltammetry response of $\mathrm{Ca}^{2+}$-ISME with varying concentrations of RuHex. (B) Calibration of $\mathrm{Ca}^{2+}$-ISME in RuHex with amperometric i-t curve (blue dots) and square wave voltammetry (red dots). (C) Cyclic voltammetry of $\mathrm{Ca}^{2+}$-ISME in $1 \mathrm{mM}$ RuHex (vs. $\mathrm{Ag} / \mathrm{AgCl}$ ). (D) Fitting of the negative feedback approach curve of the dual-function $\mathrm{Ca}^{2+}$ sensor $(\mathrm{RG}=1.5)$ with the theoretical curve. 

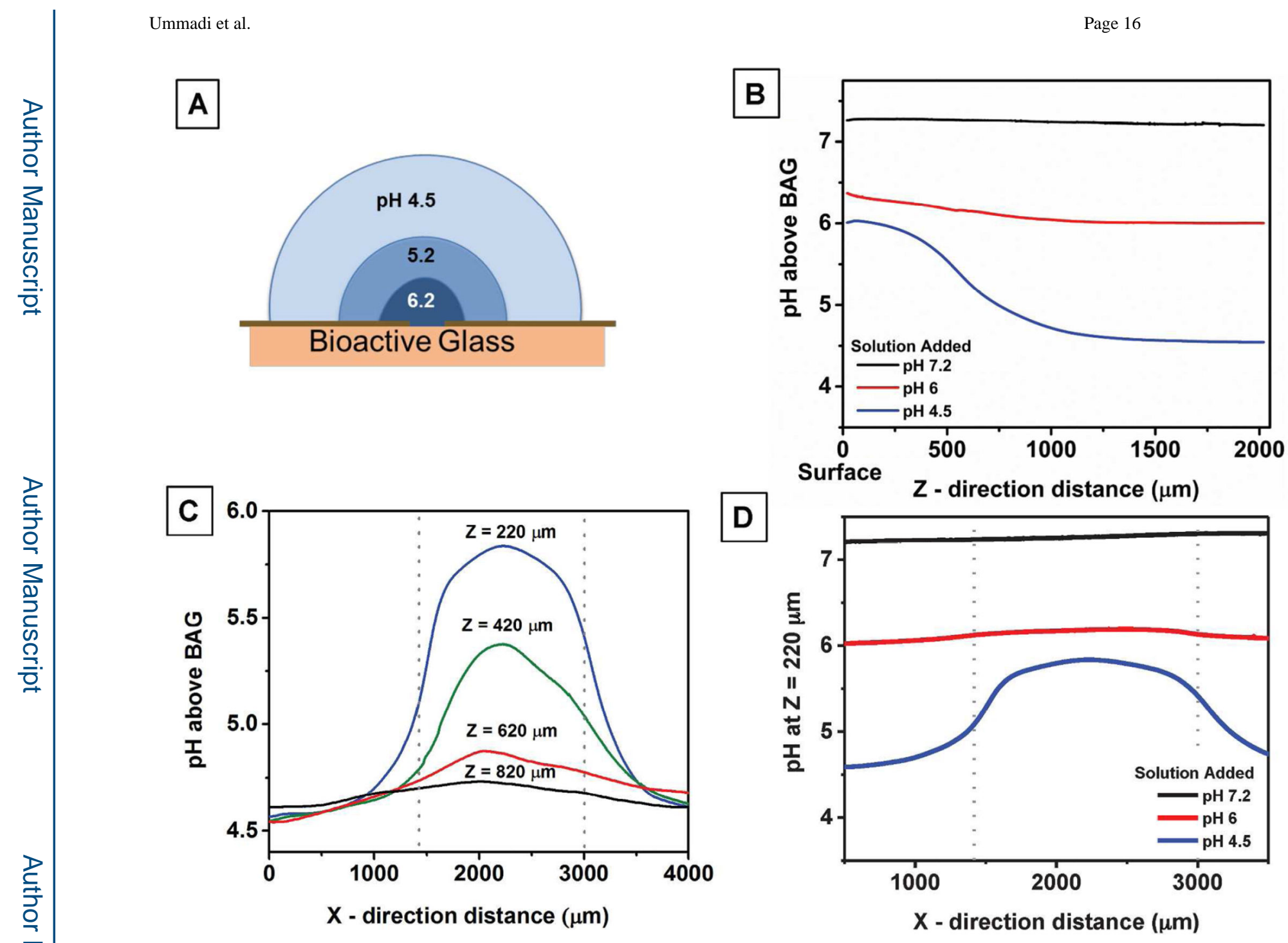

Figure 6.

(A) Schematic diagram of the $\mathrm{pH}$ profile above the exposed bioactive glass $(1.5 \mathrm{~mm}$ diameter) in acidic conditions ( $\mathrm{pH}$ 4.5). (B) Z-direction $\mathrm{pH}$ profile above the BAG surface after exposure to artificial saliva solution at various $\mathrm{pH}$ values. $\mathrm{X}$-direction $\mathrm{pH}$ profile $(\mathrm{C})$ at various heights above the BAG surface in the presence of artificial saliva solution at $\mathrm{pH} 4.5$ and (D) at $220 \mu \mathrm{m}$ above the BAG in artificial saliva at various $\mathrm{pH}$ values. Vertical dotted lines represent the exposed BAG surface. 


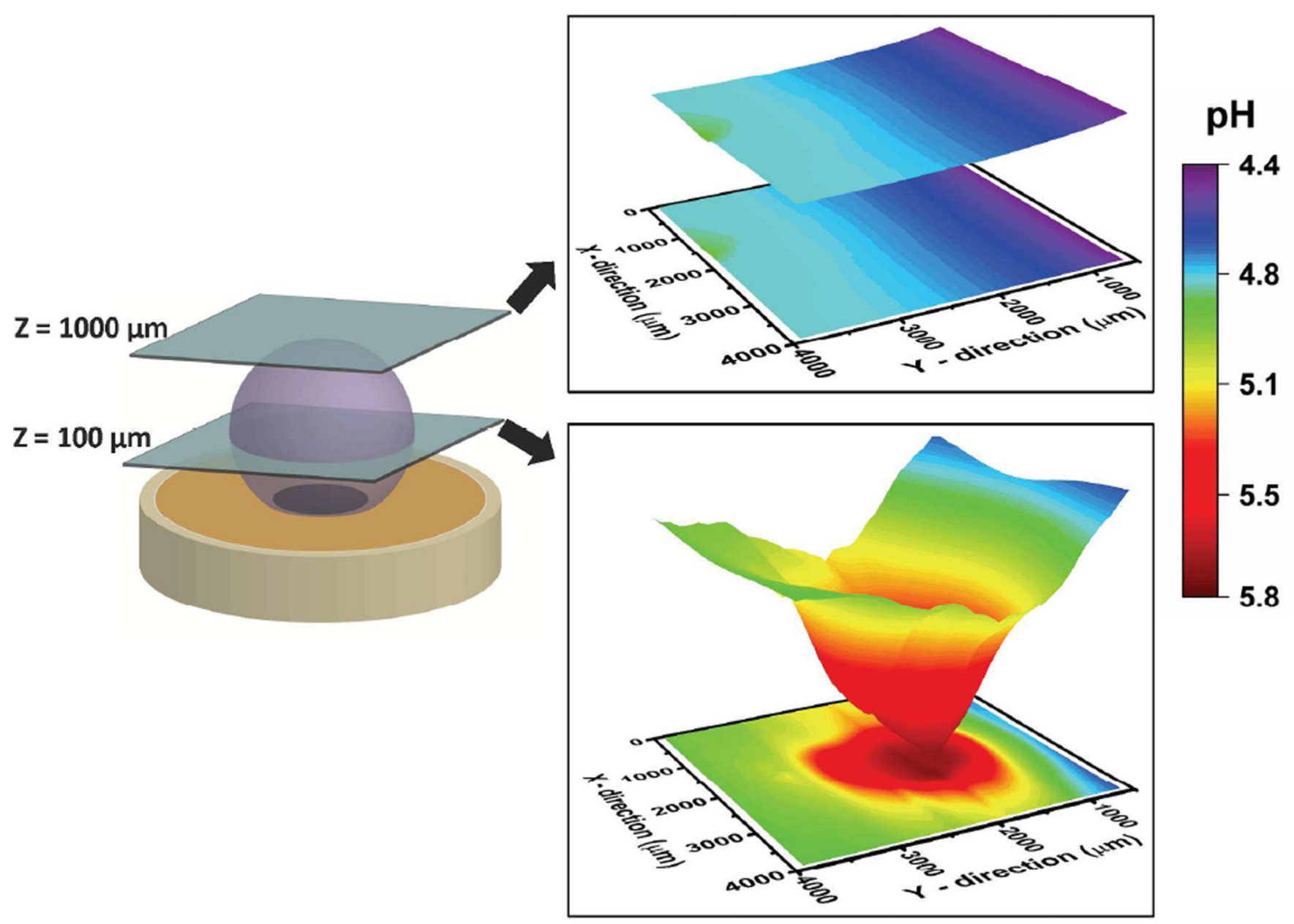

Figure 7.

Three-dimensional SECM image of $\mathrm{pH}$ distribution above the BAG surface. $\mathrm{pH}$ imaging was performed over $1.6 \mathrm{~mm}$ of the exposed BAG surface (100 and 1,000 $\mu \mathrm{m}$ above) in artificial saliva at $\mathrm{pH} 4.5$. The transparent purple sphere represents the neutralized zone produced by the BAG. 


\section{A}
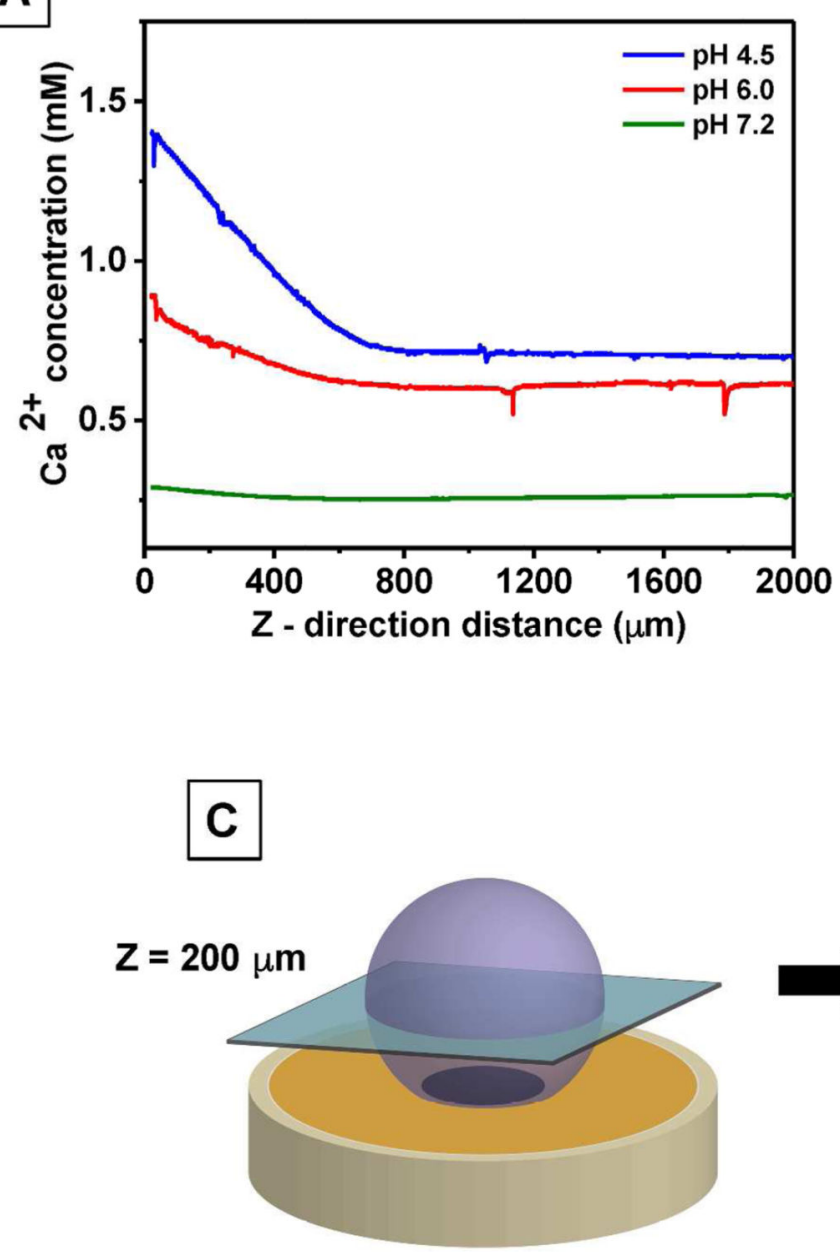

Figure 8.

\section{B}
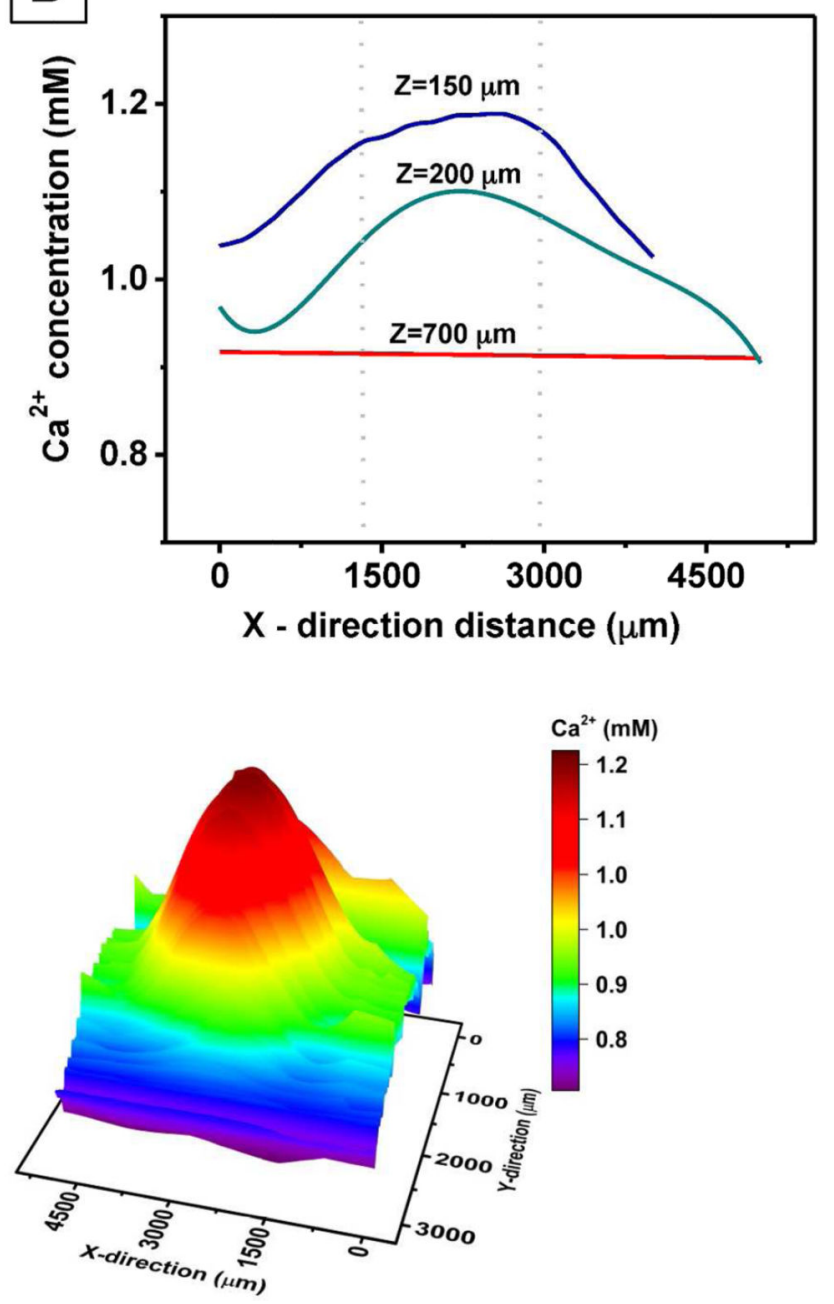

(A) Z-direction $\mathrm{Ca}^{2+}$ profile above the $\mathrm{BAG}$ substrate in the presence of artificial saliva of $\mathrm{pH} 4.5,6.0$, and 7.2. (B) $\mathrm{X}$-direction $\mathrm{Ca}^{2+}$ profile at different heights above the exposed BAG in the presence of artificial saliva at $\mathrm{pH}$ 4.5. (C) Three-dimensional SECM image of calcium ion release from the BAG surface when exposed to artificial saliva ( $\mathrm{pH} 4.5)$. The image was taken at a constant height of $200 \mu \mathrm{m}$ from the BAG surface. 


\section{Table 1}

Interference of $\mathrm{Ca}^{2+}$-ISME with $\mathrm{Mg}^{2+}, \mathrm{Na}^{+}$, and $\mathrm{K}^{+}$

\begin{tabular}{ccc}
\hline $\begin{array}{c}\text { Interfering } \\
\text { ion, } \mathbf{A}\end{array}$ & $\log \mathrm{K}_{\mathrm{Ca}^{2+}, \mathrm{A}}$ & $\log \mathrm{K}_{\mathrm{Ca}^{2+}, \mathrm{A}}$ \\
\cline { 2 - 3 } & Matched potential method & Fixed interference method \\
\hline $\mathrm{Mg}^{2+}$ & -5.88 & -5.5 \\
$\mathrm{Na}^{+}$ & -5.54 & -6.7 \\
$\mathrm{~K}^{+}$ & -6.31 & -6.1 \\
\hline
\end{tabular}


Table 2

Comparison of local and bulk pH and calcium ion concentrations.

\begin{tabular}{lcccc} 
& \multicolumn{2}{c}{$\mathbf{p H}$ measurements $\boldsymbol{a}$} & \multicolumn{2}{c}{$\mathbf{C a}^{2+}$ concentration $(\mathbf{m M})^{\boldsymbol{a}}$} \\
\cline { 2 - 5 } Saliva solution & Bulk & $\begin{array}{c}\text { Local } \\
(\mathrm{z}=\mathbf{2 0} \boldsymbol{\mu} \mathbf{m})\end{array}$ & Bulk & $\begin{array}{c}\text { Local } \\
(\mathbf{z}=\mathbf{2 0} \boldsymbol{\mu m})\end{array}$ \\
\hline pH 4.5 & $4.58 \pm 0.05$ & $6.04 \pm 0.3$ & $0.70 \pm 0.05$ & $1.40 \pm 0.10$ \\
pH 4.5 & $6.05 \pm 0.01$ & $6.37 \pm 0.1$ & $0.51 \pm 0.05$ & $0.85 \pm 0.05$ \\
pH 4.5 & $7.15 \pm 0.01$ & $7.30 \pm 0.1$ & $0.35 \pm 0.05$ & $0.35 \pm 0.10$ \\
\hline
\end{tabular}

${ }^{a}$ All concentrations are reported after $4 \mathrm{~h}$ of exposure. 